\title{
Sociodemographic and lifestyle characteristics are associated with antioxidant intake and the consumption of their dietary sources during pregnancy
}

\author{
Liisa Uusitalo ${ }^{1,2, *}$, Ulla Uusitalo², Marja-Leena Ovaskainen ${ }^{2}$, Sari Niinistö ${ }^{2,3}$, \\ Carina Kronberg-Kippilä ${ }^{2}$, Liisa Marjamäki ${ }^{1}$, Suvi Ahonen ${ }^{1,4}$, Mike G Kenward ${ }^{5}$, \\ Mikael Knip ${ }^{6,7,8}$, Riitta Veijola ${ }^{9}$ and Suvi M Virtanen ${ }^{1,2,4}$ \\ ${ }^{1}$ Tampere School of Public Health, University of Tampere, Tampere, Finland: ${ }^{2}$ Department of Health Promotion \\ and Chronic Disease Prevention, National Public Health Institute, Mannerheimintie 166, 00300 Helsinki, \\ Finland: ${ }^{3}$ Department of Public Health, University of Helsinki, Helsinki, Finland: ${ }^{4}$ Tampere University Hospital \\ Research Unit, Tampere, Finland: ${ }^{5}$ Department of Epidemiology and Population Health, Medical Statistics Unit, \\ London School of Hygiene \& Tropical Medicine, London, UK: ${ }^{6}$ Hospital for Children and Adolescents, HUS, \\ Finland: ${ }^{7}$ Department of Pediatrics, Tampere University Hospital, Tampere, Finland: ${ }^{8}$ The Juvenile Diabetes \\ Research Foundation (JDRF) Center for Prevention of Type 1 Diabetes in Finland, Turku, Oulu and Tampere, \\ Finland: ${ }^{9}$ Department of Pediatrics, University of Oulu, Oulu, Finland
}

Submitted 14 December 2007: Accepted 7 July 2008: First published online 15 August 2008

\begin{abstract}
Objective: To analyse the associations of selected sociodemographic and lifestyle factors with the intake of antioxidant nutrients and consumption of their main dietary sources among pregnant women.

Design: A population-based cohort study. Dietary intake during pregnancy was assessed by a self-administered FFQ one to three months after the delivery.

Setting: Type 1 Diabetes Prediction and Prevention (DIPP) Project.

Subjects: Subjects comprised 3730 women $(70 \cdot 1 \%$ of those invited) who entered the DIPP Nutrition Study after delivering a child at increased genetic risk for type 1 diabetes at the university hospitals in Oulu and Tampere, Finland, 1997-2002.

Results: All sociodemographic and lifestyle factors studied showed significant associations with antioxidant intake in multiple regression models adjusting for all other factors. Older and more educated women tended to have higher intake of most antioxidants. Parity was positively associated with retinol intake and inversely with vitamin C intake. Smokers had lower intakes of most antioxidants. Only the partner's education was positively associated with high intake of fruits, whereas own education was positively associated with berry consumption. Vegetable consumption was positively associated with partner's education except for women with academic education, who tended to have high vegetable consumption irrespective of partner's education.

Conclusions: Young women, smokers and those with a low education are at risk for low antioxidant intake and non-optimal food choices during pregnancy.
\end{abstract}

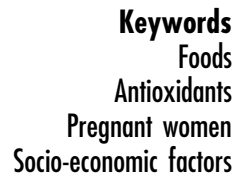

eywords

Antioxidants Socio-economic factors
Pregnancy is a period of increased oxidative stress for the new coming mother ${ }^{(1)}$. Deficiencies of antioxidant nutrients have been associated with complications of pregnancy $^{(2,3)}$. During pregnancy, the fetus is relatively protected from free radicals in the uterine environment, but faces increased oxidative action at birth ${ }^{(4)}$. Antioxidant status of the newborn is influenced by maternal dietary intake $e^{(5-11)}$. The health implications of antioxidant supply during early life are a relatively novel field of research. The role of dietary antioxidants during fetal life and early childhood in the development of type 1 diabetes and allergies is a focus of the Nutrition Study of the Type 1 Diabetes Prediction and Prevention (DIPP) Project. In recent studies, maternal vitamin $\mathrm{E}$ intake was inversely associated with responses to allergens ${ }^{(12)}$, wheezing ${ }^{(13,14)}$ and asthma ${ }^{(14)}$ in the offspring. Higher intake of $\mathrm{Zn}$ during pregnancy was associated with lower risk of wheezing ${ }^{(13)}$ and asthma ${ }^{(14)}$ in children. 
Food consumption and nutrient intake have been shown to differ by social circumstances. In general, higher socio-economic status tends to be associated with healthier food choices ${ }^{(15-17)}$ and higher nutrient intakes $^{(18,19)}$. The consequences of dietary differences during pregnancy may reach the next generation. In the present study, we analysed the effects of selected sociodemographic and lifestyle factors on the intake of antioxidant nutrients in a large cohort of pregnant Finnish women. We expected social disadvantages to be associated with a lower antioxidant intake during pregnancy. Because the influence of sociodemographic and lifestyle factors on antioxidant intake is mediated on the level of food choices, we also analysed their associations with the consumption of the main dietary sources of antioxidant nutrients.

\section{Subjects and methods}

\section{Subjects}

In the DIPP Project, a prospective population-based cohort study ${ }^{(20)}$, all newborn infants from the areas of three university hospitals in Finland are screened for HLA DQB1-conferred susceptibility to type 1 diabetes using cord blood samples ${ }^{(21)}$. All infants carrying increased genetic susceptibility are invited to a follow-up study on diabetes-associated autoantibodies, growth, viral infections and nutrition. Procedures were approved by the local ethics committees. The families signed informed written consents. The present series comprises the mothers of at-risk children born between December 1997 and December 2002 at Oulu University Hospital and between October 1997 and December 2002 at Tampere University Hospital. In this analysis baseline dietary data from 3730 mothers $(70 \cdot 1 \%$ of the mothers invited) were available (Table 1).

\section{Dietary metbods}

Dietary intake during pregnancy was assessed postnatally by a self-administered, semi-quantitative, 181-item FFQ, which has been validated specifically for the present study against $10 \mathrm{~d}$ food records in a sample of pregnant Finnish women ${ }^{(22)}$. Also in the validation study the questionnaire was completed after the delivery. The validity of the questionnaire for antioxidant nutrients was, in general, good; correlation coefficients between the two methods ranged from 0.45 for $\mathrm{Zn}$ to 0.71 for retinol. The only exception was vitamin $\mathrm{E}$, for which the correlation was only $0 \cdot 22$. The FFQ was designed to assess the entire diet over the last month before the beginning of maternity leave, i.e. the 8 th month of pregnancy. The portion sizes were based on natural units and commonly used portions identified in earlier Finnish dietary studies. The mothers received the FFQ by mail, and returned it at the first visit to the study centre three months after the delivery. A trained study doctor or nurse checked the FFQ and, if required, completed it in cooperation with the mother. All the returned FFQ forms were checked by a trained nutritionist. If there were ten or more food items with missing frequency data, the FFQ was rejected ( $n 52$ ). FFQ data were entered into a data file at a commercial dataentry service. Food consumption data were split into ingredients using information of the recipe composition for composite dishes and foods in the Finnish food composition database (FCDB) ${ }^{(23)}$. Daily intakes of energy, retinol, $\beta$-carotene, vitamin $\mathrm{C}$, vitamin $\mathrm{E}, \mathrm{Se}, \mathrm{Zn}$ and $\mathrm{Mn}$ were calculated by using the FCDB and in-house software of the National Public Health Institute. Retinol, although less well known as an antioxidant than its precursor $\beta$-carotene, is capable of inhibiting free radical reactions ${ }^{(24)}$ and was therefore included in the study. Nutrients from vitamin and mineral supplements were not included in the calculations of nutrient intake in the present analyses.

As food groups to be analysed, we selected the main dietary sources of each antioxidant nutrient among the present study population ${ }^{(25)}$. The major sources of retinol were organ meats, milk products and butter. $\beta$-Carotene came mainly from vegetables. Juice was the major source of vitamin C, followed by vegetables and fruits. Vitamin E was supplied mainly by vegetable oils, cereal products and margarine. The most important sources of Se and $\mathrm{Zn}$ were meat, milk and cereal products, and Se was supplied also by fish. Mn was provided mainly by cereal products, and also by berries.

The use of dietary supplements during the entire pregnancy was queried in a separate question on the FFQ form. The supplements which contained antioxidant nutrients were grouped into the following types: (i) vitamin $\mathrm{A}$ or $\mathrm{A} / \mathrm{D}$ supplements or cod liver oil; (ii) $\beta$-carotene supplements; (iii) vitamin $\mathrm{C}$ supplements; (iv) vitamin E or vegetable oil supplements; (v) multivitamin and mineral supplements; and (vi) mineral supplements with Mn, Se or Zn. However, due to small numbers of users in all supplement groups except for multivitamin and mineral supplements, a combined variable representing the use of any of these types of dietary supplements was used in the statistical model.

\section{Sociodemographic and lifestyle characteristics}

Information on general education (comprehensive school education and upper secondary general education), vocational education and age of both parents was registered by a structured questionnaire completed after the delivery. In preliminary single covariate analyses, vocational education was more closely associated with dietary factors than general education, and was used in the multiple covariate models. Vocational education was coded as none, vocational school or course (up to level 3 in the International Standard Classification of Education $1997^{(26)}$; typical qualifications e.g. hairdresser and construction worker), upper secondary vocational education 
Table 1 Characteristics of pregnant women who delivered a child at increased genetic risk for type 1 diabetes at the University Hospital of Oulu or Tampere, Finland, 1997-2002

\begin{tabular}{|c|c|c|c|c|}
\hline \multirow[b]{2}{*}{ Variable } & \multicolumn{2}{|c|}{$\begin{array}{l}\text { Provided dietary data } \\
\text { ( }(n 3730)\end{array}$} & \multicolumn{2}{|c|}{$\begin{array}{l}\text { Refused } \\
(n \text { 501) }\end{array}$} \\
\hline & $\%$ & $n$ & $\%$ & $n$ \\
\hline \multicolumn{5}{|l|}{ Age (years) $\dagger$} \\
\hline$<25$ & $19 \cdot 3$ & 720 & $20 \cdot 2$ & 101 \\
\hline $25 \cdot 0-29 \cdot 9$ & $34 \cdot 1$ & 1273 & $29 \cdot 1$ & 146 \\
\hline $30 \cdot 0-34 \cdot 9$ & $29 \cdot 7$ & 1108 & $27 \cdot 1$ & 136 \\
\hline$\geq 35 \cdot 0$ & $16 \cdot 8$ & 628 & $23 \cdot 6$ & 118 \\
\hline Missing & 0.0 & 1 & 0.0 & 0 \\
\hline \multicolumn{5}{|l|}{ Parity† } \\
\hline 0 & $45 \cdot 3$ & 1691 & $23 \cdot 2$ & 116 \\
\hline 1 & $31 \cdot 7$ & 1181 & $31 \cdot 1$ & 156 \\
\hline 2 & $13 \cdot 8$ & 515 & $21 \cdot 2$ & 106 \\
\hline$\geq 3$ & $8 \cdot 5$ & 317 & $21 \cdot 8$ & 109 \\
\hline Missing & 0.7 & 26 & $2 \cdot 8$ & 14 \\
\hline \multicolumn{5}{|l|}{ Degree of urbanizationt } \\
\hline Ürban & $76 \cdot 4$ & 2848 & $67 \cdot 3$ & 337 \\
\hline Semi-urban & $9 \cdot 8$ & 367 & $11 \cdot 0$ & 55 \\
\hline Rural & $13 \cdot 1$ & 489 & $19 \cdot 0$ & 95 \\
\hline Missing & 0.7 & 26 & $2 \cdot 8$ & 14 \\
\hline \multicolumn{5}{|l|}{ Place of residencet } \\
\hline Region of Tampere & $58 \cdot 7$ & 2188 & $41 \cdot 3$ & 207 \\
\hline Region of Oulu & $41 \cdot 3$ & 1541 & $58 \cdot 7$ & 294 \\
\hline \multicolumn{5}{|l|}{ Own vocational educationt } \\
\hline None & $6 \cdot 3$ & 236 & $12 \cdot 0$ & 60 \\
\hline Vocational school or course & $29 \cdot 0$ & 1082 & 33.5 & 168 \\
\hline Upper secondary vocational education & $40 \cdot 6$ & 1513 & $31 \cdot 5$ & 158 \\
\hline Academic & $21 \cdot 4$ & 800 & $12 \cdot 2$ & 61 \\
\hline Missing & $2 \cdot 7$ & 99 & $10 \cdot 8$ & 54 \\
\hline \multicolumn{5}{|l|}{ Vocational education of partnert } \\
\hline None & $5 \cdot 4$ & 203 & $7 \cdot 4$ & 37 \\
\hline Vocational school or course & $39 \cdot 5$ & 1472 & $41 \cdot 9$ & 210 \\
\hline Upper secondary vocational education & $29 \cdot 3$ & 1092 & $22 \cdot 0$ & 110 \\
\hline Academic & $21 \cdot 1$ & 788 & $15 \cdot 8$ & 79 \\
\hline Missing & $4 \cdot 7$ & 175 & $13 \cdot 0$ & 65 \\
\hline \multicolumn{5}{|l|}{ Smoking during pregnancy } \\
\hline No & $86 \cdot 2$ & 3217 & $82 \cdot 4$ & 413 \\
\hline Yes & $10 \cdot 3$ & 383 & $11 \cdot 2$ & 56 \\
\hline Missing & $3 \cdot 5$ & 130 & $6 \cdot 4$ & 32 \\
\hline \multicolumn{5}{|l|}{ BMI $\left(\mathrm{kg} / \mathrm{m}^{2}\right)$ at the first antenatal visit } \\
\hline$<21 \cdot 6$ & $23 \cdot 4$ & 873 & $-\ddagger$ & \\
\hline $21 \cdot 6-23 \cdot 5$ & $23 \cdot 6$ & 879 & & \\
\hline $23 \cdot 6-26 \cdot 2$ & $23 \cdot 5$ & 877 & & \\
\hline$>26 \cdot 2$ & $23 \cdot 5$ & 877 & & \\
\hline Missing & $6 \cdot 0$ & 224 & & \\
\hline
\end{tabular}

tThe distribution of those who provided dietary data was statistically significantly different from those who did not (Pearson's $\chi^{2}$ test): $P \leq 0 \cdot 001$.

flnformation missing, because data were collected on the FFQ form.

(levels 3 and 4; e.g. nurse, technician) and academic (levels 5 and 6; e.g. doctor, school teacher). Information on the number of earlier deliveries (parity), home municipality and maternal smoking during pregnancy was received from the Medical Birth Registries of the Oulu and Tampere University Hospitals. Home municipality was coded as urban, semi-urban or rural according to the classification of Statistics Finland ${ }^{(27)}$. Smoking during pregnancy was registered on a three-class scale (non-smoker/quit smoking during the first trimester/ smoker). As the number of quitters was small, they were aggregated with smokers. Maternal height and weight measured at the first antenatal examination were enquired on the FFQ form. BMI was calculated as weight $(\mathrm{kg})$ divided by the square of height $\left(\mathrm{m}^{2}\right)$.

\section{Statistical methods}

We did not have sociodemographic data on the families who refused to participate in the study. To assess the degree of selection, we compared the sociodemographic and health-related characteristics of those mothers whose child entered the DIPP study, but who did not provide dietary data ( $n$ 501), with the mothers who provided dietary data by the $\chi^{2}$ test.

Several of the food groups showed clear non-normality, even after logarithmic transformation $(\ln (x+0 \cdot 01))$. Derived binary variables were therefore used as outcomes in multiple logistic regression analysis, with an 'event' defined as a variable in the highest observed quartile. All of the explanatory variables were categorical, and coded as binary indicator variables. The use of 
antioxidant supplements was analysed by a similar multiple logistic regression model, the dependent variable being the use of any dietary supplement with antioxidant nutrients at any time during the pregnancy.

The intakes of all antioxidant nutrients were close to normal distribution after $\ln (x+0 \cdot 01)$ transformation. Antioxidant intakes were adjusted for energy intake by the residual method, using $\ln (x+0 \cdot 01)$-transformed variables in the models ${ }^{(28)}$. The associations of sociodemographic and lifestyle variables with antioxidant intake were analysed by multiple linear regression models, with the $\ln (x+0 \cdot 01)$-transformed energy-adjusted intake of each antioxidant as the dependent variable and the categorical sociodemographic and lifestyle variables as the explanatory variables. The predicted intakes were calculated by exponentiating the values of the linear predictor produced by the model $(0 \cdot 01$ subtracted).

Explanatory variables measured on an ordinal scale (age, parity, education and BMI) were tested for linear trend by treating them as continuous variables in the multiple regression models, one at a time. The interactions of own and partner's education on the food consumption variables were also tested. Regression models were tested for model assumptions and fit. Of the 3730 subjects, 504 (13.5\%) were excluded from statistical models because they had missing information in at least one explanatory variable. Thus the effective sample size was $3226(60 \cdot 6 \%$ of those invited to the study). Statistical analyses were performed using the SPSS for Windows statistical software package version $9 \cdot 0$ (SPSS Inc., Chicago, IL, USA).

\section{Results}

Women who did not provide dietary data differed from those who did in terms of age, parity, region, degree of urbanization, and by own and partner's education (Table 1). Women $\geq 35$ years old, with two or more children, from the northern region, living in a rural community and having no vocational education were under-represented among those providing FFQ data, whereas women expecting their first child and with academic education in the family were over-represented.

The intakes of $\beta$-carotene, vitamin $\mathrm{E}, \mathrm{Se}, \mathrm{Zn}$ and $\mathrm{Mn}$ increased linearly with age (Table 2 ), as did also the use of dietary supplements containing antioxidant nutrients (Fig. 1). Age group showed strong positive associations with the consumption of fish and shellfish and vegetable

Table 2 Sociodemographic and lifestyle factors as predictors for energy-adjusted daily intake of antioxidant nutrients by multiple linear regression models among pregnant Finnish women $(n 3226)$ participating in the Type 1 Diabetes Prediction and Prevention (DIPP) Project. Each column is based on a single model with all explanatory variables controlled for simultaneously

\begin{tabular}{|c|c|c|c|c|c|c|c|}
\hline \multirow[b]{2}{*}{ Explanatory variable } & \multicolumn{7}{|c|}{ Nutrient intaket } \\
\hline & Retinol $(\mu \mathrm{g})$ & $\beta$-Carotene $(\mu \mathrm{g})$ & Vitamin C (mg) & Vitamin E (mg) & Se $(\mu g)$ & $\mathrm{Zn}(\mathrm{mg})$ & $\mathrm{Mn}(\mathrm{mg})$ \\
\hline \multicolumn{8}{|l|}{ Age (years) } \\
\hline$<25 \ddagger$ & 630 & $3866 \S$ & 193 & $13 \cdot 9 \S$ & $76 \cdot 2 \S$ & $15 \cdot 7 \S$ & $6 \cdot 21 \S$ \\
\hline $25 \cdot 0-29 \cdot 9$ & $589^{*}$ & 3892 & 194 & $14 \cdot 1^{*}$ & $77 \cdot 1$ & $15 \cdot 9$ & $6 \cdot 55^{\star \star \star}$ \\
\hline $30 \cdot 0-34 \cdot 9$ & 607 & 4088 & 191 & $14 \cdot 5^{\star \star \star}$ & $79 \cdot 0^{\star \star \star}$ & $16 \cdot 1^{\star \star}$ & $6 \cdot 91^{\star \star \star}$ \\
\hline$\geq 35 \cdot 0$ & 595 & $4615^{\star \star \star}$ & 197 & $15 \cdot 0^{\star \star \star}$ & $79 \cdot 0^{\star \star \star}$ & $16 \cdot 1^{\star \star}$ & $7 \cdot 27^{\star \star \star}$ \\
\hline \multicolumn{8}{|l|}{ Parity } \\
\hline $0 \ddagger$ & $630 \S$ & 3866 & $193 \S$ & $13 \cdot 9$ & $76 \cdot 2$ & $15 \cdot 7$ & $6 \cdot 21$ \\
\hline 1 & $724^{\star \star \star}$ & 3817 & $176^{\star \star \star}$ & $13 \cdot 7$ & $76 \cdot 4$ & $15 \cdot 4^{\star \star}$ & $5 \cdot 84^{\star \star \star}$ \\
\hline 2 & $763^{\star \star \star}$ & 4043 & $177^{\star \star}$ & $14 \cdot 0$ & $76 \cdot 3$ & $15 \cdot 6$ & $6 \cdot 15$ \\
\hline$\geq 3$ & $863^{* * *}$ & 3909 & $161^{\star * *}$ & $13 \cdot 8$ & $77 \cdot 0$ & $15 \cdot 9$ & $6 \cdot 39$ \\
\hline \multicolumn{8}{|l|}{ Own vocational education } \\
\hline Academic $\ddagger$ & 630 & 3866 & 193 & $13 \cdot 9 \S$ & $76 \cdot 2 \S$ & $15 \cdot 7 \S$ & $6 \cdot 21 \S$ \\
\hline Upper secondary vocational education & $671^{*}$ & $3587^{\star \star}$ & 187 & $13 \cdot 5^{\star \star \star}$ & $75 \cdot 4$ & $15 \cdot 7$ & $6 \cdot 02^{*}$ \\
\hline Vocational school or course & $703^{\star * \star}$ & 3617 & $182^{\star}$ & $13 \cdot 5^{\star \star}$ & $74 \cdot 6^{*}$ & $15 \cdot 4$ & $5 \cdot 81^{\star \star \star}$ \\
\hline None & 616 & 3740 & 182 & $13 \cdot 0^{\star \star \star}$ & $73 \cdot 3^{\star \star}$ & $15 \cdot 1^{\star \star}$ & $5 \cdot 58^{\star \star \star}$ \\
\hline \multicolumn{8}{|l|}{ Vocational education of partner } \\
\hline Academic $\ddagger$ & 630 & $3866 \S$ & 193 & $13 \cdot 9 \S$ & $76 \cdot 2 \S$ & $15 \cdot 7$ & $6 \cdot 21 \S$ \\
\hline Upper secondary vocational education & 619 & $3634^{*}$ & 186 & $13 \cdot 7^{\circ}$ & $75 \cdot 6$ & $15 \cdot 7$ & $6 \cdot 24$ \\
\hline Vocational school or course & 644 & $3374^{* * *}$ & $178^{\star *}$ & $13 \cdot 5^{\star \star}$ & $74 \cdot 9^{*}$ & $15 \cdot 6$ & $5 \cdot 93^{\star \star}$ \\
\hline None & 679 & $3093^{\star * *}$ & 194 & $13 \cdot 7$ & $74 \cdot 0^{*}$ & $15 \cdot 2^{*}$ & $5 \cdot 77^{\star \star}$ \\
\hline \multicolumn{8}{|l|}{ Smoking during pregnancy } \\
\hline Noł & 630 & 3866 & 193 & $13 \cdot 9$ & $76 \cdot 2$ & $15 \cdot 7$ & $6 \cdot 21$ \\
\hline Yes & $699^{* *}$ & $3087^{* \star *}$ & $179^{\star *}$ & $13 \cdot 4^{\star \star \star}$ & $75 \cdot 1$ & $15 \cdot 3^{\star \star}$ & $5 \cdot 54^{\star \star}$ \\
\hline \multicolumn{8}{|l|}{ BMl $\left(\mathrm{kg} / \mathrm{m}^{2}\right)$ at the first antenatal visit } \\
\hline 1st quartileł & 630 & 3866 & 193 & $13 \cdot 9$ & $76 \cdot 2 \S$ & $15 \cdot 7 \S$ & $6 \cdot 21 \S$ \\
\hline 2nd quartile & 623 & 3804 & 196 & $13 \cdot 8$ & $76 \cdot 6$ & $15 \cdot 8$ & $6 \cdot 17$ \\
\hline 3rd quartile & 633 & 3908 & 201 & $13 \cdot 7$ & $77 \cdot 0$ & $15 \cdot 8$ & $6 \cdot 14$ \\
\hline 4th quartile & 622 & 4020 & 193 & $13 \cdot 7$ & $78 \cdot 9^{\star \star \star}$ & $16 \cdot 0^{*}$ & $6 \cdot 02^{*}$ \\
\hline
\end{tabular}

Mean values were significantly different from those of the reference category: ${ }^{\star} P \leq 0 \cdot 05,{ }^{* \star} P \leq 0 \cdot 01,{ }^{\star * \star} P \leq 0 \cdot 001$.

tAdjusted for degree of urbanization of the home municipality and region of birth (Oulu $v$. Tampere area).

$\ddagger$ Reference category.

$\S P$ for linear trend $\leq 0 \cdot 05$. 


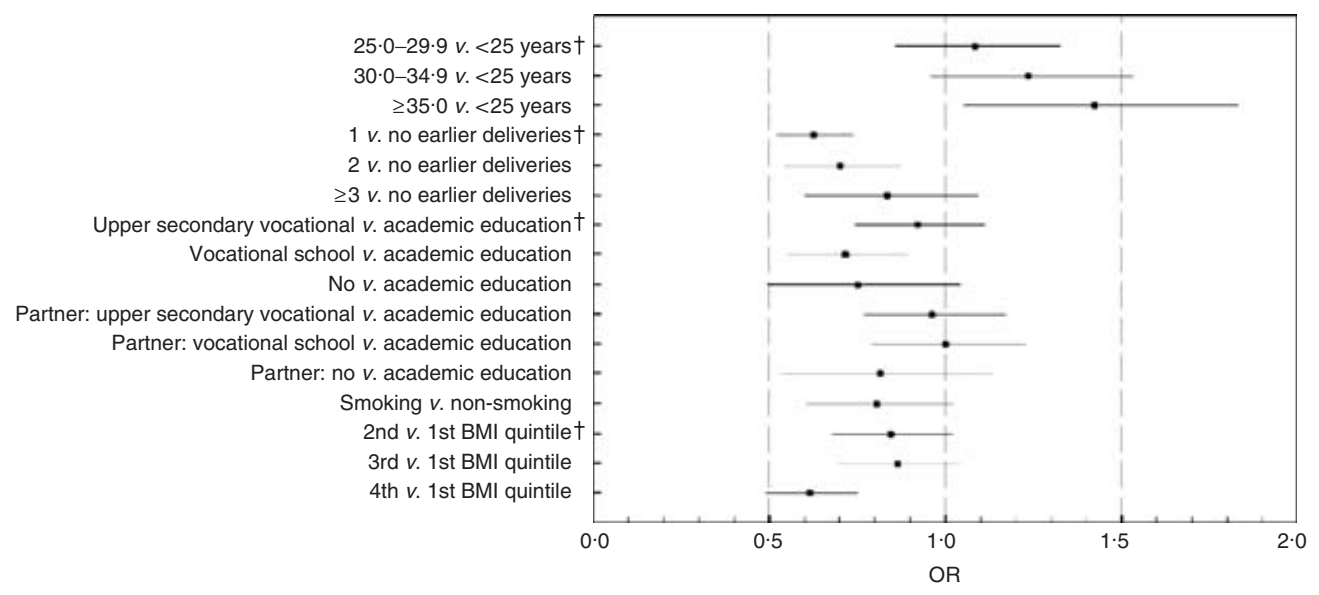

Fig. 1 Odds ratios with their $95 \%$ confidence intervals represented by horizontal bars for the consumption of dietary supplements containing antioxidant nutrients among pregnant Finnish women $(n$ 3226) participating in the Type 1 Diabetes Prediction and Prevention (DIPP) Project, adjusted for degree of urbanization of the home municipality and region of birth (Oulu $v$. Tampere area). On average, $43 \%$ had consumed these supplements at some time point during the entire pregnancy. $+P$ for linear trend $\leq 0 \cdot 05$

oils, and it was also positively associated with the consumption of butter, cereal products, vegetables, fruits and berries. On the contrary, high consumption of milk products and juice was more common among the younger pregnant women. Women who were younger than 25 years were most likely to have a high consumption of margarine (Table 3).

Parity was positively associated with the intake of retinol, and inversely with vitamin $\mathrm{C}$ intake. High consumption of organ meats, total meat products, butter, margarine and berries increased with the number of previous deliveries, whereas fruit and juice consumption was inversely associated with parity. Women expecting their first child were more likely to use antioxidant supplements than those with one or two previous deliveries.

The pregnant mother's own education level was inversely associated with retinol intake, while the positive association between education level and $\beta$-carotene intake was stronger for partner's education than own education. Both own and partner's education showed independent positive associations with the intakes of vitamin $\mathrm{E}, \mathrm{Se}, \mathrm{Zn}$ and $\mathrm{Mn}$, but the associations were stronger for own education level. Own education level was positively associated with the consumption of fish and shellfish and berries, and inversely associated with the consumption of organ meats, milk products and margarine. On the contrary, fruit consumption was positively associated with partner's education, but not with own education. There was an interaction between own and partner' education $(P=0 \cdot 04$, data not shown) indicating that vegetable consumption was positively associated with partner's education except for women with academic education, who tended to have high vegetable consumption irrespective of partner's education. Interactions terms of own and partner's education were not significant for any other food group $(P>0 \cdot 05)$. The use of antioxidant supplements showed a linear positive association with own but not partner's education.

Women who had smoked during pregnancy had a higher intake of retinol, but lower intakes of $\beta$-carotene, vitamin $\mathrm{C}$, vitamin $\mathrm{E}, \mathrm{Zn}$ and $\mathrm{Mn}$ than non-smokers. Smokers tended to consume more organ meats, total meat products, margarine and juice than non-smokers. Smokers were unlikely to have a high consumption of berries and fruit. BMI measured at the first antenatal examination was positively associated with the intakes of Se and $\mathrm{Zn}$, and inversely with Mn intake. BMI showed a linear positive association with the consumption of meat products, and a strong inverse linear association with berry consumption. BMI was inversely associated with the use of antioxidant supplements.

\section{Discussion}

All analysed sociodemographic and lifestyle factors were independently associated with the intake of antioxidant nutrients during pregnancy. Age, level of education and smoking status were the most important predictors of antioxidant intake, while the associations with parity and BMI were less consistent. Young age, low education level and smoking predicted a low antioxidant intake compared with other women.

The principal strengths of our study are the large, population-based cohort, use of an FFQ assessing total dietary intake and validated specially for the target population group, and a broad selection of explanatory variables. The population recruited consists of mothers of all newborn infants born at two university hospitals in Finland, selected only on the basis of genetic susceptibility for type 1 diabetes in the child. Because virtually all 
Table 3 Sociodemographic and lifestyle factors as predictors for the consumption of foods by multiple logistic regression models among pregnant Finnish women ( $n$ 3226) participating in the Type 1 Diabetes Prediction and Prevention (DIPP) Project. Each column is based on a single model with all explanatory variables controlled for simultaneously

\begin{tabular}{|c|c|c|c|c|c|c|c|c|c|c|c|c|}
\hline & $\begin{array}{l}\text { Organ } \\
\text { meats }\end{array}$ & $\begin{array}{c}\text { Meat } \\
\text { products, total }\end{array}$ & $\begin{array}{l}\text { Fish and } \\
\text { shellfish }\end{array}$ & $\begin{array}{c}\text { Milk } \\
\text { products }\end{array}$ & Butter & Margarine & Oil & $\begin{array}{l}\text { Cereal } \\
\text { products }\end{array}$ & Vegetables & Fruits & Berries & Juice \\
\hline 75th percentile of consumption $(\mathrm{g} / \mathrm{d})$ & 9 & 198 & 33 & 1113 & 19 & 15 & 12 & 230 & 324 & 264 & 33 & 365 \\
\hline Explanatory variable & \multicolumn{12}{|c|}{ OR for being in the highest quartile of food consumptiont } \\
\hline \multicolumn{13}{|l|}{ Age (years) } \\
\hline$<25 \ddagger$ & $1 \cdot 00 \S$ & 1.00 & $1.00 \S$ & $1 \cdot 00 \S$ & $1 \cdot 00 \S$ & $1 \cdot 00$ & $1 \cdot 00 \S$ & $1 \cdot 00$ & $1 \cdot 00 \S$ & $1 \cdot 00 \S$ & $1 \cdot 00 \S$ & $1 \cdot 00 \S$ \\
\hline $25 \cdot 0-29 \cdot 9$ & $1 \cdot 23$ & 1.01 & $1 \cdot 11$ & $1 \cdot 11$ & $1 \cdot 13$ & $0 \cdot 75^{\star}$ & $1 \cdot 52^{\star *}$ & $1 \cdot 31^{*}$ & 1.09 & $1 \cdot 27$ & 1.04 & 1.00 \\
\hline $30 \cdot 0-34 \cdot 9$ & $1 \cdot 51^{\star *}$ & $1 \cdot 21$ & $1 \cdot 71^{\star \star \star}$ & 0.83 & $1 \cdot 36^{\star}$ & $0.72^{*}$ & $1 \cdot 95^{\star \star \star}$ & $1 \cdot 36^{\star}$ & $1 \cdot 35^{*}$ & $1 \cdot 43^{\star \star}$ & $1 \cdot 18$ & $0.73^{*}$ \\
\hline$\geq 35 \cdot 0$ & $1 \cdot 46^{\star}$ & 1.00 & $2 \cdot 36^{\star \star \star}$ & $0 \cdot 62^{\star \star}$ & $1 \cdot 34$ & $0 \cdot 73^{*}$ & $2 \cdot 10^{\star \star *}$ & $1 \cdot 38^{*}$ & $1 \cdot 69^{\star \star \star}$ & $1 \cdot 45^{\star}$ & $1 \cdot 59^{\star *}$ & $0 \cdot 64^{\star *}$ \\
\hline \multicolumn{13}{|l|}{ Parity } \\
\hline $0 \neq$ & $1.00 \$$ & $1.00 \$$ & $1 \cdot 00$ & $1 \cdot 00$ & $1.00 \S$ & $1.00 \$$ & 1.00 & $1 \cdot 00$ & $1 \cdot 00$ & $1.00 \$$ & $1.00 \$$ & $1 \cdot 00 \$$ \\
\hline 1 & $1 \cdot 42^{\star \star \star}$ & $1 \cdot 55^{\star \star \star}$ & 0.87 & $0 \cdot 84$ & $1 \cdot 36^{\star \star}$ & $1 \cdot 27^{*}$ & $1 \cdot 15$ & $0 \cdot 84$ & 0.94 & $0 \cdot 68^{\star \star \star}$ & 1.01 & 0.88 \\
\hline 2 & $1 \cdot 52^{\star \star \star}$ & $1 \cdot 49^{\star \star}$ & 0.88 & $0 \cdot 80$ & $1 \cdot 27$ & $1 \cdot 22$ & $1 \cdot 15$ & $0 \cdot 83$ & $1 \cdot 18$ & $0 \cdot 68^{\star \star}$ & 1.09 & 0.80 \\
\hline$\geq 3$ & $1 \cdot 56^{\star \star}$ & $1 \cdot 60^{\star *}$ & 0.80 & 0.95 & $1 \cdot 62^{\star \star}$ & $1 \cdot 45^{\star}$ & $1 \cdot 14$ & $1 \cdot 34$ & $1 \cdot 24$ & $0 \cdot 44^{\star * *}$ & $1 \cdot 78^{\star \star \star}$ & $0 \cdot 76$ \\
\hline \multicolumn{13}{|l|}{ Own vocational education } \\
\hline Academic $\neq$ & $1 \cdot 00 \S$ & 1.00 & $1.00 \S$ & $1 \cdot 00 \S$ & 1.00 & $1 \cdot 00 \S$ & 1.00 & 1.00 & $1 \cdot 00$ & $1 \cdot 00$ & $1 \cdot 00 \S$ & 1.00 \\
\hline Upper secondary vocational education & $1 \cdot 32^{*}$ & $1 \cdot 15$ & $0 \cdot 76^{*}$ & $1 \cdot 19$ & 1.03 & $1 \cdot 50^{* *}$ & 0.85 & $1 \cdot 05$ & $0 \cdot 84$ & 0.99 & 0.87 & 1.09 \\
\hline Vocational school or course & $1 \cdot 55^{\star \star}$ & $1 \cdot 13$ & $0 \cdot 70^{\star \star}$ & $1 \cdot 42^{*}$ & $1 \cdot 09$ & $1 \cdot 55^{\star *}$ & 0.78 & $1 \cdot 11$ & 0.92 & $1 \cdot 03$ & $0.69^{\star *}$ & $1 \cdot 08$ \\
\hline None & $1 \cdot 26$ & 0.99 & $0 \cdot 68$ & $1 \cdot 37$ & 0.72 & $1 \cdot 30$ & 0.84 & $1 \cdot 20$ & 1.09 & $1 \cdot 01$ & $0.46^{\star \star}$ & $1 \cdot 14$ \\
\hline \multicolumn{13}{|l|}{ Vocational education of partner } \\
\hline Academic $\ddagger$ & 1.00 & 1.00 & $1 \cdot 00$ & 1.00 & 1.00 & $1 \cdot 00$ & $1 \cdot 00$ & $1 \cdot 00$ & $1 \cdot 00 \S$ & $1.00 \S$ & $1 \cdot 00$ & 1.00 \\
\hline Upper secondary vocational education & $1 \cdot 01$ & 1.09 & $0 \cdot 80^{*}$ & $1 \cdot 01$ & $1 \cdot 02$ & $0 \cdot 91$ & 0.91 & $1 \cdot 01$ & 0.85 & $0 \cdot 80$ & 0.90 & 0.96 \\
\hline Vocational school or course & 0.91 & 0.98 & $0 \cdot 81$ & 1.05 & 1.09 & $1 \cdot 04$ & 1.05 & $0 \cdot 85$ & $0 \cdot 64^{\star * *}$ & $0 \cdot 65^{\star * *}$ & $0 \cdot 81$ & 0.93 \\
\hline None & $1 \cdot 17$ & 1.08 & 0.67 & 0.95 & 0.87 & 0.90 & 0.95 & $1 \cdot 01$ & $0 \cdot 55^{\star \star}$ & $0 \cdot 74$ & $0 \cdot 72$ & $1 \cdot 52^{*}$ \\
\hline \multicolumn{13}{|l|}{ Smoking during pregnancy } \\
\hline Noł & $1 \cdot 00$ & 1.00 & 1.00 & $1 \cdot 00$ & 1.00 & $1 \cdot 00$ & $1 \cdot 00$ & $1 \cdot 00$ & 1.00 & 1.00 & $1 \cdot 00$ & $1 \cdot 00$ \\
\hline Yes & $1 \cdot 38^{\star}$ & $1 \cdot 38^{*}$ & 0.84 & 1.03 & 0.91 & $1 \cdot 39^{\star}$ & $1 \cdot 13$ & $0 \cdot 82$ & $0 \cdot 70^{*}$ & $0 \cdot 89$ & $0 \cdot 51^{\star \star \star}$ & $1 \cdot 34^{*}$ \\
\hline \multicolumn{13}{|l|}{ BMI $\left(\mathrm{kg} / \mathrm{m}^{2}\right)$ at the first antenatal visit } \\
\hline 1st quartile $\ddagger$ & $1 \cdot 00$ & $1 \cdot 00 \S$ & $1 \cdot 00$ & 1.00 & 1.00 & $1 \cdot 00$ & $1 \cdot 00$ & $1 \cdot 00$ & 1.00 & $1 \cdot 00$ & $1 \cdot 00 \S$ & $1 \cdot 00$ \\
\hline 2nd quartile & 1.07 & 0.88 & 0.90 & $1 \cdot 02$ & 0.97 & $1 \cdot 06$ & 0.91 & 0.83 & 0.91 & 0.95 & $0.74^{*}$ & 1.08 \\
\hline 3rd quartile & 1.03 & $1 \cdot 16$ & $0 \cdot 84$ & $1 \cdot 16$ & $1 \cdot 27^{\star}$ & $1 \cdot 14$ & $1 \cdot 06$ & $1 \cdot 01$ & $1 \cdot 19$ & 0.94 & $0 \cdot 78^{*}$ & $1 \cdot 30^{*}$ \\
\hline 4th quartile & $1 \cdot 11$ & $1 \cdot 20$ & 0.84 & $1 \cdot 21$ & 0.94 & 0.93 & 0.97 & $0 \cdot 83$ & $1 \cdot 13$ & 0.91 & $0 \cdot 64^{\star \star \star}$ & $1 \cdot 01$ \\
\hline
\end{tabular}

Significantly different from the reference category: ${ }^{*} P \leq 0.05,{ }^{* *} P \leq 0.01,{ }^{* \star *} P \leq 0.001$.

tAdjusted for degree of urbanization of the home municipality and region (Oulu $v$. Tampere area).

†Reference category.

$\S P$ for linear trend $\leq 0.05$. 
children in Finland are born in public hospitals (E Vuori, STAKES, personal communication), the women invited in the study are likely to be an unbiased sample of all new mothers in the catchment areas of the two university hospitals, concerning their social position. The validation study showed that our FFQ overestimated the intakes of most foods and nutrients, but ranked subjects reasonably well according to their dietary intakes ${ }^{(22)}$. Because the intake figures of antioxidant nutrients are probably overestimates, we did not compare them with recommended dietary intakes.

A potential limitation of our study is selective response rate according to sociodemographic and lifestyle factors. The FFQ, as a method requiring average levels of written and numerical comprehension, may be unsuitable for the most disadvantaged respondents ${ }^{(29)}$. The bias is likely to produce underestimates of the true differences between population groups ${ }^{(30)}$. The groups with a high proportion of non-responders tend to be those with less healthy dietary habits. The responders to a dietary questionnaire are likely to be more health-conscious than the nonresponders, and consequently to be more similar to the groups with higher response rates in terms of their food consumption. Our study sample was biased towards higher education and smaller number of children. It is likely that the true gradient in dietary choices by education level and parity is even larger than our results suggest. On the contrary, the response rate was lowest in women aged 35 years or older, who also had the most healthful diets. In this age group, our results may be overestimates of the true differences.

The intake of most antioxidant nutrients increased linearly with age, as did the consumption of wholesome foods with a high nutrient density. The positive association of age with $\beta$-carotene resulted from the high consumption of vegetables. The positive association of age with vitamin $\mathrm{E}$ intake is explained by the consumption of vegetable oils, cereal products, fish and vegetables, with Se by fish and cereal products, and with Mn by cereal products and berries. Zn was supplied mainly by milk, cereal and meat products, but of these only the consumption of cereal products was associated with age. Vitamin C intake did not differ by age group in spite of the positive association of age and fruit consumption. This is explained by the inverse association of age with the consumption of juice. The present findings are in line with previous research on pregnant women; age has been shown to be positively related to the consumption of vegetables ${ }^{(31)}$ and to dietary intakes of $\beta$-carotene, vitamin $\mathrm{C}$ and $\mathrm{Zn}^{(30)}$.

The high retinol intake of multiparous women was explained by their high consumption of meat products. Specifically, the most important source of retinol in the present study was liver, the consumption of which was discouraged in the Finnish dietary guidelines for pregnant women because of the teratogenic effect of high retinol intake $^{(32)}$. The lower vitamin $\mathrm{C}$ intake of multiparous women resulted from the inverse associations of parity with the consumption of fruits and juice. Similarly, in an earlier study, primiparous women consumed more fruit than others ${ }^{(31)}$.

Education was positively associated with the intakes of $\beta$-carotene and vitamin $\mathrm{A}$, but not with vitamin $\mathrm{E}$ and $\mathrm{Zn}$ among Austrian pregnant women. Vitamin $\mathrm{C}$ intake was highest in the mid-education group ${ }^{(33)}$. Vitamin $\mathrm{C}$ intake has been positively associated with education ${ }^{(34)}$ and with husband's occupation. Husband's occupation also correlated positively with the intakes of $\mathrm{Zn}$ and carotene, but not with vitamins $\mathrm{A}$ and $\mathrm{E}^{(35)}$. In the present study, education level was one of the most important determinants of antioxidant intake. Retinol was the only one of the analysed nutrients that was inversely associated with education, reflecting the higher liver consumption of less educated women. The associations of own and partner's education with food consumption were not uniform. Partner's education was a better predictor of fruit consumption of the pregnant mother, while own education was positively associated with the consumption of berries. Vegetable consumption was, in general, more closely associated with partner's education than own, but this did not apply to academic women; they tended to be high vegetable consumers even if the education level of their partner was low. Unfortunately we did not have information on income, but the contrasting relationships of own and partner's education with food consumption may result from a complex interplay of education and family income. Education develops habits, skills, resources and abilities that enable people to create a lifestyle that promotes health, while income indicates available economic resources $^{(36)}$ and can have effects on health which are independent of education ${ }^{(33,37)}$. We speculate that woman's own education is associated with an inclination to consume healthy foods, while the education of the male parent is probably a more important determinant of available economic resources, especially in families with young children. Economic considerations might explain why fruit and vegetable consumption is more dependent on partner's than own education. There is plenty of evidence showing that fruits and vegetables are often considered expensive ${ }^{(38,39)}$ and that their consumption tends to be associated with income ${ }^{(16,31,40)}$. Among vegetables, however, also low-price alternatives can be found, and this could in part enable the high vegetable consumption of academic women irrespective of their partner's education. On the contrary, it is a common practice in Finland to pick berries for free, and this may explain why the pregnant mother's berry consumption is independent of partner's education level.

The diets of smokers were relatively poor of antioxidant nutrients compared with non-smokers, the only exceptions being retinol and Se. The high retinol supply resulted from the consumption of organ meats. Smokers 
tended to be high consumers of meat products, resulting in similar Se intake to non-smokers. Smokers also had high consumption of margarine and juice, but still their intakes of vitamin $\mathrm{E}$ and vitamin $\mathrm{C}$ were lower than those of non-smokers. Smoking was inversely associated with vegetable and berry consumption, which accounts for the low intakes of $\beta$-carotene and $\mathrm{Mn}$. Similar findings have been reported for vegetables, retinol $^{(41)}$, carotene, vitamin $\mathrm{C}^{(30,41)}$, vitamin $\mathrm{E}^{(41)}$ and $\mathrm{Zn}{ }^{(30,41)}$, unadjusted for other factors. In the study by Mathews et $a l^{(30)}$, the association between smoking and $\mathrm{Zn}$ intake was not significant after adjustment for age.

Among all of the explanatory variables tested, BMI measured at the beginning of the pregnancy seemed the least important predictor. The differences in antioxidant intake were small. The high consumption of meat products was reflected in the positive associations with Se and $\mathrm{Zn}$, and the low berry consumption in the inverse association with $\mathrm{Mn}$. There are at least two possible explanations for the weak associations between BMI and food consumption. Women who were overweight in early pregnancy may have changed their diets towards recommendations, or BMI may be more closely associated with physical activity than with dietary habits. Similarly, neither pre-pregnancy weight nor current BMI was associated with the intake of antioxidant nutrients during pregnancy in an earlier study ${ }^{(30)}$.

We analysed the combined effect of several sociodemographic and lifestyle factors on the intake of antioxidant nutrients, and found a substantial degree of variation in the individual intakes of $\beta$-carotene, $\mathrm{Mn}$, retinol and vitamin $C$. For $\beta$-carotene, there was almost a threefold difference between the lowest and the highest intake predicted by the multiple regression model. However, the intake patterns were not uniform for different antioxidants. Retinol showed the most distinct pattern, as, unlike all of the other antioxidants, it was positively associated with parity and smoking, and inversely associated with education. These associations were explained by the higher liver consumption of the women who already had children, smoked during pregnancy or had a low education.

The supplemental consumption of antioxidant nutrients tended to further accentuate the sociodemographic differences in intake, since the same factors were associated with both high dietary intake and supplement use. Age and own level of education were positively associated with the use of dietary supplements containing antioxidant nutrients, whereas parity and BMI were inversely associated with supplement use. In Austrian ${ }^{(33)}$ and Finnish ${ }^{(34)}$ populations of pregnant women, neither age nor education was significantly associated with dietary supplement use. The sample size in our study is considerably larger than in the two earlier studies, which may account for the differing results. In all three studies, multivitamin preparations were among the most frequently used supplement types. In Finnish dietary guidelines for pregnant women, multivitamin supplements are recommended only in connection with a very inadequate diet. Supplements with vitamin A should not be used during pregnancy ${ }^{(32)}$.

In conclusion, young women, smokers and those with a low level of education in the family are at risk for low intake of antioxidant nutrients during pregnancy. The significance of this finding is emphasized by the fact that foods rich in antioxidant nutrients tend to be foods with a high density of other nutrients and dietary fibre as well, with a low content of refined sugar and often with a low content of saturated fat. Correspondingly, a low dietary intake of antioxidant nutrients may often indicate a refined, energy-dense diet. In fact, fruits, vegetables, berries, wholegrain cereal products, margarine, fish and low-fat milk products, all of which are important sources of antioxidant nutrients, are recommended in the Finnish dietary guidelines for pregnant women. In the maternal care system, attention should be paid to nutritional counselling and guiding recommended food choices among the vulnerable groups. However, Travers ${ }^{(42)}$ has stated that 'as long as professional practice continues to place primary emphasis on changing individuals without consideration of the context within which they work, the potential remains high for victim blaming on the part of professionals, and guilt on the individual who is unable to live up to expectations'. In further research, the effect of economic resources, along with other social constraints, on the food choices of families with children should be addressed.

\section{Acknowledgements}

None of the authors had financial or personal interests in any company or organization sponsoring the research at the time the research was done. The work was supported by the Academy of Finland (grants 63672, 79685,79686, 80846, 201988, 210632), the Finnish Diabetes Association, the Finnish Diabetes Research Foundation, the Finnish Pediatric Research Foundation, the Häme Foundation of the Finnish Culture Fund, the Juho Vainio Foundation, the Yrjö Jahnsson Foundation, Medical Research Funds of Turku, Oulu and Tampere University Hospitals, the Juvenile Diabetes Research Foundation (grants 197032, 4-1998-274, 4-1999-731, 4-2001-435), the Novo Nordisk Foundation and EU Biomed 2 (BMH4-CT98-3314), Doctoral Programs for Public Health, and the Jalmari and Rauha Ahokas Foundation.

L.U. designed the analyses, wrote the manuscript, performed the statistical analyses and processed the data. U.U. designed the analyses, processed the data and evaluated the results. M.-L.O. designed the analyses and evaluated the results. S.N., C.K.-K. and S.A. processed the data and evaluated the results. L.M. processed the data. M.G.K. evaluated the results. M.K. designed the study and 
evaluated the results. R.V. processed the data. S.M.V. designed the study and evaluated the results.

We thank the DIPP research staff for excellent collaboration. We express our gratitude to the families who participated in the study.

\section{References}

1. Chen X \& Scholl TO (2005) Oxidative stress: changes in pregnancy and with gestational diabetes mellitus. Curr Diab Rep 5, 282-288.

2. McArdle HJ \& Ashworth CJ (1998) Micronutrients in fetal growth and development. Br Med Bull 55, 499-510.

3. Henriksen $T$ (2006) Nutrition and pregnancy outcome. Nutr Rev 64, Suppl., S19-S23.

4. Robles R, Palomino N \& Robles A (2001) Oxidative stress in the neonate. Early Hum Dev 65, Suppl., S75-S81.

5. Gazala E, Sarov B, Hershkovitz E, Edvardson S, Sklan D, Katz M, Friger M \& Gorodischer R (2003) Retinol concentration in maternal and cord serum: its relation to birth weight in healthy mother-infant pairs. Early Hum Dev 71, 19-28.

6. Zapata CL, Melo MR \& Donangelo CM (1997) Maternal, placental and cord zinc components in healthy women with different levels of serum zinc. Biol Neonate 72, 84-93.

7. Karakilcik AZ, Aksakal M, Baydas G, Sozen R, Ayata A \& Simsek M (1996) Plasma $\beta$-carotene concentrations in pregnancies, newborn infants and their mothers. J Pak Med Assoc 46, 77-80.

8. Dejmek J, Ginter E, Solansky I, Podrazilova K, Stavkova Z, Benes I \& Sram RJ (2002) Vitamin C, E and A levels in maternal and fetal blood for Czech and Gypsy ethnic groups in the Czech Republic. Int J Vitam Nutr Res $\mathbf{7 2}$, 183-190.

9. Wasowicz W, Wolkanin P, Bednarski M, Gromadzinska J, Sklodowska M \& Grzybowska K (1993) Plasma trace element ( $\mathrm{Se}, \mathrm{Zn}, \mathrm{Cu}$ ) concentrations in maternal and umbilical cord blood in Poland. Relation with birth weight, gestational age, and parity. Biol Trace Elem Res 38, 205-215.

10. Takser L, Lafond J, Bouchard M, St-Amour G \& Mergler D (2004) Manganese levels during pregnancy and at birth: relation to environmental factors and smoking in a Southwest Quebec population. Environ Res 95, 119-125.

11. Gonzalez-Corbella MJ, Lopez-Sabater MC, CastelloteBargallo AI, Campoy-Folgoso C \& Rivero-Urgell M (1998) Influence of caesarean delivery and maternal factors on fatsoluble vitamins in blood from cord and neonates. Early Hum Dev 53, Suppl., S121-S134.

12. Devereux G, Barker RN \& Seaton A (2002) Antenatal determinants of neonatal immune responses to allergens. Clin Exp Allergy 32, 43-50.

13. Litonjua AA, Rifas-Shiman SL, Ly NP, Tantisira KG, RichEdwards JW, Camargo CA Jr, Weiss ST, Gillman MW \& Gold DR (2006) Maternal antioxidant intake in pregnancy and wheezing illnesses in children at $2 \mathrm{y}$ of age. Am J Clin Nutr 84, 903-911.

14. Devereux G, Turner SW, Craig LCA, McNeill G, Martindale S, Harbour PJ, Helms PJ \& Seaton A (2006) Low maternal vitamin $\mathrm{E}$ intake during pregnancy is associated with asthma in 5-year old children. Am J Respir Crit Care Med 174, 499-507.

15. Groth MV, Fagt S \& Brondsted L (2001) Social determinants of dietary habits in Denmark. Eur J Clin Nutr 55, 959-966.

16. Laaksonen M, Prättälä R, Helasoja V, Uutela A \& Lahelma $\mathrm{E}$ (2003) Income and health behaviours. Evidence from monitoring surveys among Finnish adults. I Epidemiol Community Health 57, 711-717.

17. De Irala-Estevez J, Groth M, Johansson L, Oltersdorf U, Prättälä R \& Martinez-Gonzales MA (2000) A systematic review of socioeconomic differences in food habits in Europe: consumption of fruit and vegetables. Eur J Clin Nutr 54, 706-714.

18. Shimakawa T, Sorlie P, Carpenter MA, Dennis B, Tell GS, Watson R \& Williams OD (1994) Dietary intake patterns and sociodemographic factors in the Atherosclerosis Risk in Communities study. Prev Med 23, 769-780.

19. Roos E, Prättälä R, Lahelma E, Kleemola P \& Pietinen P (1996) Modern and healthy? Socioeconomic differences in the quality of diet. Eur J Clin Nutr 50, 753-760.

20. Kupila A, Muona P, Simell T et al. (2001) Feasibility of genetic and immunological prediction of type 1 diabetes in a population-based birth cohort. Diabetologia $\mathbf{4 4}$, 290-297.

21. Ilonen J, Reijonen H, Herva E, Sjöroos M, Iitiä A, Lövgren T, Veijola R, Knip M, Åkerblom HK \& The Childhood Diabetes in Finland (DiMe) Study Group (1996) Rapid HLA-DQB1 genotyping for four alleles in the assessment of diabetes risk in the Finnish population. Diabetes Care 19, 795-800.

22. Erkkola M, Karppinen M, Javanainen J, Räsänen L, Knip M \& Virtanen SM (2001) Validity and reproducibility of a food frequency questionnaire for pregnant Finnish women. $\mathrm{Am}$ $J$ Epidemiol 154, 466-476.

23. National Public Health Institute (2007) Fineli $^{\circledR}$ - Finnish Food Composition Database. http://www.fineli.fi

24. Livrea MA \& Tesoriere L (1998) Antioxidant activity of vitamin A within lipid environments. In Subcellular Biochemistry. vol. 30: Fat-soluble Vitamins, pp. 113-143 [PJ Quinn and VE Kagan, editors]. New York: Plenum Press.

25. Uusitalo L, Kenward MG, Virtanen SM, et al. (2008) Intake of antioxidant vitamins and trace elements during pregnancy and risk of advanced $\beta$-cell autoimmunity in the child. Am J Clin Nutr (In the Press).

26. United Nations Educational, Scientific and Cultural Organization (1997) International Standard Classification of Education. http://portal.unesco.org/education/en/files/ 9405/10371902320ISCED_A_word_doc/ISCED_A\%2Bword. doc (accessed December 2007).

27. Statistics Finland (2005) Statistical grouping of municipalities. http://www.stat.fi/meta/kas/til_kuntaryhmit_en.html (accessed November 2007).

28. Willett W (1998) Nutritional Epidemiology, 2nd ed. New York: Oxford University Press.

29. Turrell G \& Najman JM (1995) Collecting food-related data from low socioeconomic groups: how adequate are our current research designs? Aust J Public Health 19, 410-416.

30. Mathews F, Yudkin P, Smith RF \& Neil A (2000) Nutrient intakes during pregnancy: the influence of smoking status and age. J Epidemiol Community Health 54, 17-23.

31. Bodnar LM \& Siega-Riz AM (2002) A Diet Quality Index for Pregnancy detects variation in diet and differences by sociodemographic factors. Public Health Nutr 5, 801-809.

32. Hasunen $\mathrm{K}$, Kalavainen $\mathrm{M}$, Keinonen $\mathrm{H}$, Lagström $\mathrm{H}$, Lyytikäinen A, Nurttila A, Peltola T \& Talvia S (2004) The Child, Family and Food. Nutrition Recommendations for Infants and Young Children as well as Pregnant and Breastfeeding Mothers. Helsinki: Publications of the Ministry of Social Affairs and Health.

33. Freisling H, Elmadfa I \& Gall I (2006) The effect of socioeconomic status on dietary intake, physical activity and body mass index in Austrian pregnant women. J Hum Nutr Diet 19, 437-445. 
34. Erkkola M, Karppinen M, Järvinen A, Knip M \& Virtanen SM (1998) Folate, vitamin D, and iron intakes are low among pregnant Finnish women. Eur J Clin Nutr 52, 742-748.

35. Wynn S, Wynn A, Doyle W \& Crawford M (1994) The association of maternal social class with maternal diet and the dimensions of babies in a population of London women. Nutr Health 9, 303-315.

36. Mirowsky J \& Ross C (1998) Education, personal control, lifestyle and health. A human capital hypothesis. Res Aging 20, 415-449.

37. Rahkonen O, Arber S, Lahelma E, Martikainen P \& Silventoinen K (2000) Understanding income inequalities in health among men and women in Britain and Finland. Int J Health Serv 30, 27-47.
38. Attree P (2005) Low-income mothers, nutrition and health: a systematic review of qualitative evidence. Matern Child Nutr 1, 227-240.

39. Dittus KL, Hillers VN \& Beerman KA (1995) Benefits and barriers to fruit and vegetable intake: relationship between attitudes and consumption. J Nutr Educ 27, 120-126.

40. Axelson ML (1986) The impact of culture on food-related behavior. Annu Rev Nutr 6, 345-363.

41. Rogers I, Emmett P, Baker D \& Golding J (1998) Financial difficulties, smoking habits, composition of the diet and birthweight in a population of pregnant women in the South West of England. ALSPAC Study Team. Avon Longitudinal Study of Pregnancy and Childhood. Eur J Clin Nutr 52, 251-260.

42. Travers KD (1996) The social organization of nutritional inequities. Soc Sci Med 43, 543-553. 